\title{
DURKHEIM E WEBER: \\ UMA PERSPECTIVA INTRODUTÓRIA ACERCA DA RELIGIÃO
}

\author{
Durkheim and Weber: \\ An Introductory Perspective on Religion
}

\author{
Kaique Cardoso ${ }^{1}$ \\ Donizete Rodrigues ${ }^{2}$
}

\section{RESUMO:}

A religião é um processo dinâmico, sofrendo mudanças constantes, para atender as novas exigências individuais e coletivas, no contexto das sociedades modernas, marcadas pela forte competitividade de um mundo globalizado de bens simbólicos-religiosos e práticas do sagrado (Bourdieu). Buscaremos neste texto discutir algumas concepções primordiais de Max Weber e Émile Durkheim a respeito da religião, enquanto subsistema de práticas econômicas, culturais ou causais que influenciam de algum modo o tecido social. Estes autores clássicos são ainda imprescindíveis no estudo de problemáticas religiosas atuais, evidenciando, desta forma, o caráter atemporal das suas obras. Ao expor, mesmo que brevemente, estas duas vertentes de compreensão do fenómeno religioso, pretendemos dar uma contribuição para a discussão sociológica do papel das religiões no atual contexto contemporâneo.

Palavras-chave: Weber; Durkheim; teorias sociológicas; religião.

\begin{abstract}
:
Religion is a dynamic process, undergoing constant changes, to adjust to the new individual and collective demands, in the context of modern societies, marked by the strong competitiveness of a globalized world of symbolic-religious goods and sacred practices (Bourdieu). In this text, based on Weber and Durkheim, we will discuss some conceptions of religion, considered as a subsystem of economic, cultural, or causal practices, which influence, in some way, the social sphere. These classical authors are still indispensable in the study of current religious problems, evidencing thus the timeless character of their theorical works. Although briefly, in approaching these two understanding of the religious phenomenon, we intend to make a contribution to the sociological discussion of the role of religions in the contemporary social context.
\end{abstract}

Keywords: Weber; Durkheim; sociological theories; religion.

\footnotetext{
${ }^{1}$ Mestre em Ciências Sociais. Doutorando em Sociologia - Universidade da Beira Interior. E-mail: cardosokm@gmail.com. Bolseiro Protocolo Santander Totta/UBI.

${ }^{2}$ Professor Associado (Livre-Docente) da Universidade da Beira Interior e Investigador-sênior do Centro em Rede de Investigação em Antropologia/Universidade Nova de Lisboa - E-mail: donizetti.rodrigues@gmail.com
}

REVISTARELEGENSTHRÉSKEIA - 2019 - UFPR 
Introdução

A relevância da ampla discussão acerca da religião se deve à grande influência que este subsistema cultural exerce sobre os indivíduos e sobre as formas de organização social. Por isso, a grande maioria dos cientistas sociais, clássicos e modernos, valoriz(ar)am o vasto e complexo sistema simbólico-religioso e suas implicações para as condições objetivas e subjetivas de constituição e mudanças das sociedades e culturas. Consequentemente, surgiram diversas orientações teóricas - histórica, materialista, culturalista, substantivista, funcionalista, economicista -, materializadas em inúmeras e diversificadas áreas de investigação empíricas (RODRIGUES, 2007).

Estando a religião presente em todas as sociedades humanas, através de cosmologias, ritos/rituais, crenças e práticas - e em suas diferentes facetas, localidades e temporalidades acaba por se tornar um importante campo de estudo das ciências sociais, em geral, e da sociologia, em particular. Por esta razão, a religião tem sido um objeto de estudo primordial, atraindo a atenção não só de autores clássicos (Augusto Comte, Karl Marx, Émile Durkheim, Max Weber), mas, também, modernos e contemporâneos, como Mircea Eliade, Clifford Geertz, Pierre Bourdieu, Bryan Wilson, Daniéle Hérvieu-Léger, entre outros.

Ao compreender a religião - e seus desdobramentos enquanto temática de interesse sociológico - é possível analisar incontáveis implicações e relações estabelecidas na criação, organização e processo de mudança do sistema social. A religião, enquanto uma realidade social, influenciando e influenciada pelo poder, real e simbólico, exercido pelas instituições, fiéis, práticas, é um elemento crucial na sociedade. As suas influências e valores afetam os indivíduos e estão fortemente presentes na educação, na política, na economia, na saúde, entre outros domínios.

A religião é um processo dinâmico, sofrendo mudanças constantes, para atender as novas exigências individuais e coletivas, no contexto das sociedades modernas, marcadas pela forte competitividade de um mundo globalizado de bens simbólicos-religiosos e práticas do sagrado (BOURDIEU, 1986). Buscaremos neste texto discutir algumas concepções primordiais de Max Weber e Émile Durkheim a respeito da religião, enquanto subsistema de práticas econômicas, culturais ou causais que influenciam de algum modo o tecido social. Ao expor, mesmo que brevemente, estas duas vertentes teóricas de compreensão do religioso, pretendemos dar uma contribuição para a discussão teórica do papel das religiões no atual contexto contemporâneo.

\section{Émile Durkheim (1858-1917)}


Considerado um dos 'founding fathers' da Sociologia, Durkheim é um dos autores centrais na constituição e disseminação dessa disciplina, enquanto ciência independente, autônoma e com objeto de estudo específico.

Émile Durkheim centra a sua análise da religião na importância do coletivo, na “consciência coletiva'. De acordo com a sua teoria funcionalista, a religião é um subsistema cultural/social, um produto da sociedade; é uma força vital e unificadora, possuindo uma função conciliadora entre os conflitantes interesses existentes no interior da sociedade (DURKHEIM, 2002 [1912]).

Segundo Durkheim, a regularidade social só é possível por causa (e é resultante) da 'consciência colectiva', da pressão exterior (coerção) que as formas coletivas de pensar, agir e sentir exercem sobre os indivíduos. Sendo um conceito chave na sua obra, 'consciência coletiva' é definida como força moral exterior que se impõem/sobrepõe ao puro interesse do indivíduo - submissão do indivíduo ao grupo. Conjunto de normas morais, regras, condutas, valores, atitudes, prescrições, costumes, crenças, signos e símbolos, partilhados pelo grupo/comunidade/sociedade/religião, que a sociedade espera sejam compartilhados pelos seus membros, criando, desta forma, formas padronizadas de comportamento. Os valores e ideais que regulam a vida colectiva são consideradas/respeitadas pelos indivíduos como sendo de caráter sagrado/religioso, onde o deus supremo é a própria sociedade; ou seja, a sociedade é a fonte divina de autoridade moral, até porque é ela a entidade que o protege e garante sua sobrevivência. A ausência, ou apenas enfraquecimento da consciência colectiva, pode provocar crise, caos, sinais evidentes de desregulação da sociedade, que Durkheim denomina de anomia: desestruturação do marco normativo que regula as relações entre os distintos subsistemas sociais (RODRIGUES, 2007).

O funcionalismo durkheimiano parte de uma concepção em que a sociedade é constituída por diferentes partes, como pequenas e diferentes engrenagens que, juntas, propiciam o equilibro e integração da vida social. Assim, esta teoria considera as partes fundamentais e necessárias para o estabelecimento, funcionamento e integração de um todo, maior, amplo e complexo.

Uma das suas principais contribuições sociológicas é o conceito de fato social. Durkheim define e caracteriza fatos sociais como entidades reais, autónomas e passíveis de constatação empírica. Ao sistematizar, metodologicamente, o fato social enquanto objeto das investigações sociológicas, o define como

“... toda maneira de agir, fixa ou não, suscetível de exercer sobre o indivíduo uma coerção exterior; ou então ainda, que é geral na extensão de uma 
sociedade dada, apresentando uma existência própria, independente das manifestações individuais que possa ter" (DURKHEIM, 1974, p. 11).

Os fatos sociais podem ser observados e compreendidos nos modos de pensar, agir e sentir que são regularmente adotados pelos indivíduos no contexto do grupo/sociedade. Logo, o fato social é exterior ao indivíduo e dotado de um poder coercitivo.

Em As Regras do Método Sociológico (1974), Durkheim elabora as primeiras regras metodológicas sistemáticas, a aplicação do método científico na investigação empírica: a delimitação do objeto de estudo, a afirmação da cientificidade e objetividade do conhecimento sociológico, o rigor metodológico e a exigência da neutralidade do investigador.

A metodologia para investigação dos fatos sociais é muito importante para Durkheim (1974). Inicialmente, deve-se considerar o fato social enquanto uma coisa externa ao indivíduo, sem pré-noções, independentes, evitando quaisquer ideias falsas e opiniões formadas fora do âmbito científico. O autor enfatiza que se deve tratar o facto social na lógica do cientista natural, assumindo a total ignorância e buscando a prática cartesiana de dúvida metódica. Porém, por se tratar do 'reino' humano, há algumas peculiaridades - os cientistas investigariam as causas, efeitos e regularidades, com vistas à descoberta de leis gerais sobre o funcionamento das sociedades humanas (QUINTANEIRO et al., 2012).

Através da concepção de fato social, o autor busca compreender a sociedade, a moral, a religião e o suicídio. Na obra $O$ Suicídio, publicada em 1897, defende que o suicídio é um facto social ligado às motivações individuais permeadas pelas influências do coletivo. Assim, o suicídio deve ser explicado em termos das características da sociedade em que os indivíduos se encontram inseridos e da sua pertença social e religiosa.

A vida social dos indivíduos é de extrema relevância para Durkheim, sendo a religião uma das formas primeiras de manutenção dessa coletividade. O mundo é, por si só, representado a partir de crenças religiosas, pois estas fornecem elementos constituintes da sociedade, evidenciando, assim, as forças anônimas da religião, que se perpetuam através do tempo e do espaço, fornecendo também uma base de ação das condutas em sociedade (GABATZ \& ZEFERINO, 2018).

As Formas Elementares da Vida Religiosa, publicada em 1912, é uma obra magistral, onde Durkheim cria a teoria funcionalista do sistema simbólico-religioso. Há uma forte valorização da história e da etnografia no estudo da religião. Defende que a religião é a chave para a compreensão da sociedade. Portanto, o objectivo central da sociologia é estudar as múltiplas formas de inter-relações existentes entre religião e sociedade. As colectividades 
humanas não produzem apenas 'bens materiais', mas também sistemas de representações simbólicas-religiosas, formando o ethos, a essência do grupo/sociedade. A sua definição de religião centra-se, fundamentalmente, na função social da religião - como 'coisa' colectiva, é um elemento de integração social, um subsistema de crenças e práticas que unem a comunidade. Segundo Durkheim, a religião ajuda o indivíduo a pensar-se como parte de um grupo, como sociedade (RODRIGUES, 2007).

Durkheim (2002) explicita uma profunda investigação a respeito do totemismo australiano, considerando-o como a religião mais primitiva e simples; possuindo, no entanto, elementos suficientes que possibilitam compreender as religiões modernas (e contemporâneas) e os percursos históricas que estas estabelece(ra)m.

"Devemos começar por remontar à sua forma mais simples, procurar dar conta dos caracteres pelos quais se define sua existência, e fazer ver depois o modo como pouco a pouco se desenvolveu e complicou, a forma como se tornou aquilo que é no momento em que a consideramos" (DURKHEIM, 2002, p. 7).

Na sociedade, há várias inter-relações que se estabelecem, em diferentes níveis, entre os diferentes elementos do fenómeno (social) não susceptíveis de isolamento e fragmentação. A análise do religioso envolve uma gama enorme de elementos constituintes. É necessário, por isso, compreender a moral, o sagrado, o profano, os dogmas, os ritos, os mitos, os cultos, as cerimonias, entre outras práticas, revelando, assim, a complexidade de um sistema formado por diversificados elementos.

"Procede-se como se a religião formasse uma espécie de entidade indivisível, quando ela é um todo formado de partes, em sistema mais ou menos complexos de mitos, de dogmas, de ritos, de cerimonias. Ora, um todo só pode ser definido por referência as partes que o formam" (DURKHEIM, 2002, p. 39).

Estes elementos, uma vez articulados, em menor ou maior escala, originam as práticas religiosas, sejam elas animistas, totemistas, cristãs, entre outras. Porém, como enfatizado, a religião por si mesma é uma força sagrada do coletivo e suas representações, crenças e símbolos retratam e refletem essencialmente a própria sociedade (DURKHEIM, 2002).

Como afirmaram Beriain \& José Luis (1998),

"La religión es antes que nada un sistema de nociones por médio de las cuales los indivíduos se representan la sociedade, de la que son membros, y las relaciones, oscuras pero íntimas, que sostienen com ella" (p. 87).

Durkheim (2002) se distancia de um racionalismo positivista, valorizando a importância da religião e suas implicações para a sociedade. Ao considerar a religião, seja totêmica ou não, enquanto um reflexo da sociedade, compreende a religião como o primeiro sistema de 
pensamento, sendo algo eminentemente social e coletivo. Ao criar seus deuses, totens ou sistemas sagrados, as sociedades de cada época expressam suas mais puras necessidades, sejam elas sociais ou morais.

Dessa forma, Durkheim realiza um exercício de compreensão sociológica das bases elementares da religião. Compreender o totemismo, na perspectiva do autor, enquanto a religião mais primitiva e simples, possibilita ao cientista social o contato e acesso a diferentes elementos constituintes da religião, tal como as noções de sagrado e profano, os ritos, rituais, entre outros.

A religião tradicional não é misteriosa, incognoscível nem incompreensível. Esta percepção somente ocorre devido à crença moderna e científica de que há uma ordem natural das coisas. Sendo assim, ao ser objeto de uma investigação sociológica, com método, regra e cientificidade, a religião deve ser analisada e interpretada a partir de suas evidências sociais e culturais intrínsecas.

$\mathrm{Na}$ análise sociológica, compreender as diferentes partes para entender o todo (perspectiva holística), na lógica funcionalista de Durkheim, o sagrado/profano, as crenças, os ritos ganham uma enorme importância. As crenças expressam os elementos sagrados, com virtude, poder e graça, distanciando qualquer manifestação profana. Os ritos relacionam-se às crenças e possuem regras de condutas e moral que se tornam imprescindíveis para qualquer forma de relacionamento com o sagrado (HÉRVIEU-LÉGER \& WILLAIME, 2009).

O sagrado e o profano são duas conceitualizações teóricas e práticas cotidianas elementares para a constituição de qualquer religião; por isso, são de grande relevância em qualquer análise sociológica do fenómeno religioso. Como oposição ao profano, o sagrado é considerado como superior - pode se apossar de plantas, animais ou mesmo pessoas, fazendo com que esses passem a pertencer ou possuir algum caráter divino.

“O sagrado se compõe de um conjunto de coisas, de ritos e crenças, quando as coisas sagradas mantêm umas com as outras relações de coordenação e subordinação, de modo a formar um sistema com certa unidade" (ARON, 1999, p. 312).

Após abordar algumas contribuições de Émile Durkheim, é altura de recorreremos também a Max Weber, teórico de fundamental importância para a Sociologia que, assim como Durkheim, possui vasta produção científica sobre o fenómeno religioso.

Max Weber (1864-1920) 
Ao compreender a religião enquanto algo prático da realidade cotidiana dos indivíduos, o alemão Max Weber afasta qualquer misticismo que ronda os estudos dessa temática, fazendo com que a investigação sociológica trate seu objeto de estudo de forma científica e objetivamente observável, afastando qualquer perspectiva transcendente e irracional (ARON, 1999).

Ao falar da importância histórica da religião, Weber (1922) faz uma relação direta entre modernidade-racionalidade-pensamento científico-reforma protestante (com a sua ética do trabalho árduo/hard work) e o desenvolvimento do capitalismo (de base calvinista), sistema primordial de produção de riqueza. Na perspectiva weberiana, a relação modernidade/secularização/desencantamento do mundo implica, fundamentalmente, duas mudanças principais na maneira de pensar (e explicar) o mundo: a dessacralização das atitudes humanas e a racionalização do pensamento, ou seja, o uso da lógica e não do simbólicoreligioso na explicação dos fatos sociais (RODRIGUES, 2007).

Max Weber é de suma importância nas discussões envolvendo a religião e o papel da economia na organização da sociedade, uma vez que investiga a fundo a relação entre a ascese religiosa e o surgimento do capitalismo ocidental. Compreende a religião como um modo de agir comunitário, que impõe diferentes sistemas de regulação da vida que influenciam na esfera econômica (HÉRVIEU-LÉGER; WILLAIME, 2009).

$\mathrm{O}$ capitalismo analisado por Weber está diretamente vinculado à vida prática. Em países como Alemanha, Holanda e Estados Unidos, havia uma dominação da propriedade fabril e dos cargos mais qualificados por parte dos protestantes. As práticas religiosas são marcadas por uma racionalização prática da conduta dos indivíduos em sociedade, através de métodos e sistemas de ordenação. Como consequência - e seguindo esta perspectiva - Weber centrou a sua análise sociológica nas relações entre estas causalidades (QUINTANEIRO et al., 2012).

Weber (2004) faz um estudo aprofundado acerca do espírito do capitalismo através da ética protestante, ou seja, verifica em que medida a religião possibilitou e influenciou o surgimento e consolidação do sistema capitalista ocidental através de um "ethos" - entendido como mentalidade, costumes, traços comportamentais. O 'ethos' é definido como "um sistema de disposições que imprimem uma orientação determinada à ação que a estruturam em uma verdadeira conduta de vida" (HÉRVIEU-LÉGER; WILLAIME, 2009, p. 111). Esta forma econômica capitalista consiste na união entre o desejo pelo lucro e uma disciplina rigorosa (ascetismo), que é oriunda do "ethos" puritano de inspiração calvinista.

O protestantismo, em suas diferentes vertentes, foi compreendido e aplicado de diferentes formas. Contudo, algumas premissas contribuíram diretamente para o surgimento do 
capitalismo ocidental, uma vez que as ações sociais e racionais dos indivíduos em busca do lucro resultaram em novas formas de comportamento econômico. Tais ações sociais possuíam, em sua essência, valores e concepções de cunho moral e religioso - o indivíduo buscava a todo o momento racionalizar seus ganhos, custos, gastos, seu tempo (o 'time is money' de Benjamim Franklin) e dedicar-se com afinco à vocação profissional. Sendo assim, o mundo torna-se uma obrigação e a missão do crente, após tornar-se um reformador consiste em modifica-lo e fazer com que seja um local de ideais ascéticos (QUINTANEIRO et al, 2012).

Weber em sua vasta obra, busca construir uma teoria sociológica que intenta compreender as ações sociais dos indivíduos; essas ações são dotadas de sentido e, por isso, passíveis de interpretação. Categoriza quatro tipos de ações sociais, sendo elas: ação social racional referente a fins; ação social racional referente a valores; ação social afetiva; e ação social tradicional (WEBER, 2005). Tais tipos ideais possibilitam compreender as relações entre indivíduos de diferentes origens e influências religiosas, dando suporte para um paralelo analítico a respeito da ética religiosa em relação ao comportamento econômico. Desse modo, para Weber (2004), o capitalismo ocidental é a junção entre uma ética de trabalho racionalista que busca o lucro, porém tal racionalismo é oriundo de um "ethos" religioso.

As sociedades possuem valores, morais, normas e condutas que, em grande medida, relacionam-se com os elementos constituintes do religioso. Logo, em uma análise sociológica de qualquer sociedade, esbarra-se na necessidade de uma compreensão da religião, enquanto elemento que influencia e altera a vida cotidiana dos indivíduos. Assim, as concepções religiosas são cruciais para a compreensão da organização econômica, jurídica, política, entre outras.

O capitalismo ocidental surge no século XVI, em países com forte confissão protestante, evidenciando, desde cedo, uma maior afinidade para o desenvolvimento das indústrias e expansão do comércio...

“... os chefes de empresas, os detentores de capitais, bem como os representantes das camadas superiores qualificadas de mão de obra, e mais ainda, o pessoal técnico e comercial com nível superior de escolaridade das empresas modernas, são na grande maioria protestantes" (LALLEMENT, 2008, p. 300).

Por isso, nota-se um melhor desempenho e desenvolvimento econômico em países e regiões com vínculos protestantes, respaldando, dessa forma, a tese central de Weber a respeito da essência do "espírito" com viés religioso do capitalismo. O trabalho, compreendido enquanto uma vocação divina, incentiva o indivíduo a se dedicar com afinco à suas atividades laborais, buscando assim maiores recursos e melhorias econômicas e financeiras. 
Concomitantemente, observa-se um menor desenvolvimento econômico, industrial e comercial em países com um "ethos" religioso oriundo de preceitos católicos. Na perspectiva weberiana, os católicos valoriza(va)m a pobreza, propagando aos seus fiéis que para conquistarem o reino dos céus era necessário devoção e pobreza durante a vida terrena. Sendo assim, inserir-se no mundo dos grandes negócios, ou mesmo compreender a profissão enquanto uma vocação, não era essencial para as práticas e modo de vida católico. Desta forma, a ascese católica de fuga do mundo, ação contemplativa e pobreza, diferentemente dos movimentos protestantes, não buscava uma racionalização metódica; e isso reflete diretamente na organização social e nas condições económicas de diferentes regiões e países (QUINTANEIRO et al., 2012).

$\mathrm{Na}$ perspectiva da sociologia weberiana, a religião, ao exercer diferentes poderes sobre os indivíduos, acaba por influenciar, em vários sentidos, a vida e ações dos mesmos, uma vez que gera intensos laços, vínculos e formas de estar no mundo. Uma das importantes formas de disseminação e vivência de tais preceitos acontece através do agrupamento de indivíduos em torno de uma 'seita' ou 'igreja' (WEBER, 2005); por isso, a 'comunalização religiosa' é investigada e analisada por Weber, constituindo, assim, dois outros importantes tipos ideais de sua vasta obra.

A 'igreja' é uma instituição burocratizada de salvação que administra os bens religiosos, possui autoridade e busca manter, em seu meio, o maior número possível de indivíduos, todos sob o controle institucional e divino. Possuindo corpo de sacerdotes profissionais, por vezes com estilo de vida definido e hierarquia galgada através de uma longa carreira, a 'igreja' visa alcançar a todos os indivíduos, ultrapassando quaisquer barreiras e fronteiras de diferenciação social. O culto da 'igreja' é baseado em dogmas, oriundos de escrituras sagradas, possibilitando, assim, que a comunidade participante dissemine as vivências, práticas, estruturas e preceitos de sua igreja. A 'seita', por sua vez, é compreendida a partir de um agrupamento voluntário de indivíduos, uma associação qualificada em que há busca de pureza religiosa e espiritual entre seus membros e práticas. Não intenta, como a 'igreja', aglomerar grande quantidade de indivíduos, uma vez que sua formação é mais restritiva, rejeitando também qualquer forma de controle institucional (RODRIGUES, 2007).

O mundo ocidental, na perspectiva weberiana, é entendido enquanto berço de uma racionalização, de valores que se tornaram universais e do local em que um "ethos" religioso encontrou condições, materiais e ideológicas, favoráveis e essenciais para o surgimento do capitalismo. O ocidente vem enfrentando um declínio nas atitudes e comportamentos estritamente religiosos, resultando, assim, num desencantamento da religião perante o mundo 
moderno. Sendo assim, o processo de racionalização no ocidente é um importante elemento constituinte da própria modernidade, que influencia a economia, a organização social e determina o cotidiano dos indivíduos.

Como consequência da modernização e racionalização, Weber (2005) ressalta que há um intrínseco processo de desencantamento do mundo, em que a ciência anula a existência das forças misteriosas, tornando tudo inteligível e compreensível sem a intervenção do sagrado. A magia é substituída pelo conhecimento científico e por formas de organização racional e burocrática, contribuindo assim para o processo de intelectualização, inerente à modernidade.

Porém, diferentemente desta análise weberiana, nota-se um desmembramento das ações racionais através do religioso; ou seja, o comportamento racional tornou-se necessário e regra para a sobrevivência e manutenção da vida moderna capitalista. O racionalismo, inicialmente oriundo de um "ethos" religioso, tornou-se independente e desvinculado de qualquer forma, crença ou prática religiosa. No contexto moderno, o cálculo, a estratégia, a burocratização e formalização acabam sendo os princípios elementares da racionalidade vigente (LALLEMENT, 2008).

Desta forma, é imprescindível ampliar a discussão e analisar as múltiplas formas de interrelações entre religião e sociedade. A secularização e também a laicidade despontam enquanto debates atuais e necessários, uma vez que, contrariando a perspectiva de que a religião perderia sua importância em meio ao avanço científico, nota-se hoje, no contexto da (pós)modernidade, um fortalecimento e intensificação das crenças, práticas e instituições religiosas (RODRIGUES, 2017).

\section{Apontamentos finais}

Durkheim ao sistematizar a Sociologia enquanto ciência, estrutura também uma metodologia de pesquisa que demarca os estudos sobre o papel da religião nas sociedades, sejam elas primitivas ou modernas. Daí a sua atualidade teórica e metodológica.

O contexto atual, moderno/contemporâneo, suscita uma infinidade de crenças e práticas religiosas e estas podem ser compreendidas e analisadas através de uma linha temporal, onde encontramos semelhanças e mutações a respeito do processo de compreensão sociológica da religião. Por isso, Durkheim é ‘eterno’ teoricamente: como autor clássico, é imprescindível na análise do fenómeno simbólico religioso, no contexto das sociedades modernas/contemporâneas ou das sociedades indígenas aculturadas. 
A religião é um sistema de símbolos, signos e significados que exercem algum efeito moral sobre os indivíduos. Durkheim (2002) ressalta que a religião está relacionada com a origem e ligações iniciais da organização social, acabando por representar os valores morais e interesses sociais presentes em determinados agrupamentos. Perspectivada por uma dualidade entre sagrado e profano - enquanto elementos opostos, mas complementares - possibilita uma coesão social e solidariedade entre os indivíduos e sua sociedade. Compreendendo a sociedade enquanto um sistema amplo, complexo e com diferentes influências, a religião possibilita uma integração entre os indivíduos, com evidentes implicações na vida pessoal, social, econômica e espiritual.

Por sua vez, segundo a interpretação sociológica weberiana, o surgimento do capitalismo está associado a um contexto único, no qual um 'ethos' religioso, de cunho moralista, se depara com condições objetivas de expansão e acumulação de capital. A análise das ações dos indivíduos, dos meios e fins toma grandes proporções na obra weberiana, evidenciando, assim, uma racionalidade vinculada ao cálculo que se aplica em diferentes esferas da vida cotidiana.

É pertinente realçar que a religião, as crenças, práticas e símbolos estão presentes em todas as sociedades, exercendo diferentes formas de influência ou mesmo dominação. Consequentemente, há inúmeras perspectivas sociológicas sobre o papel da religião na(s) sociedade(s). É o caso do 'desencantamento do mundo' weberiano, resultado de intensos processos de racionalização e modernidade, vivenciados com maior intensidade no ocidente (PIERUCCI, 1998). No entanto, a religião, longe de ser colocado apenas na esfera privada e familiar dos indivíduos, num processo de 'reencantamento do mundo' (RODRIGUES, 2017), continua hoje demarcando e influenciando incontáveis aspectos da vida coletiva cotidiana e com expressiva participação e influencia no espaço público (HABERMAS, 2003).

\section{Referência Bibliográfica}

ARON, R. As etapas do pensamento sociológico. 5. ed. São Paulo: Martins Fontes, 1999. BERIAIN, J.; JOSÉ LUIS, I. (Eds.). Para comprender la teoría sociológica. Navarra: Verbo Divino, 1998.

Bourdieu, Pierre (1986). Economia das Trocas Simbólicas. São Paulo, Editora Perspective.

DURKHEIM, É. As regras do método sociológico: São Paulo: Companhia editora nacional, 1974.

DURKHEIM, É. As formas elementares da vida religiosa: o sistema totemico na Austrália.

OEIRAS: Celta Editora, 2002. 
GABATZ, C.; ZEFERINO, J. As Contribuições de Émile Durkheim para Compreender a Religião na Contemporaneidade. Correlatio, v. 16, n. 2, p. 339, 19 fev. 2018.

Habermas, Jünger (2003). Mudança Estrutural na Esfera Pública. Rio de Janeiro, Tempo Brasileiro.

HÉRVIEU-LÉGER, D.; WILLAIME, J.-P. Sociologia e Religião: abordagens clássicas. Aparecida: Ideias \& Letras, 2009.

LALlEMENT, M. História das ideias sociológicas: das origens a Max Weber. 4. ed. Petrópolis, Rio de Janeiro: Editora Vozes, 2008.

PIERUCCI, A. F. Secularização em Max Weber: Da contemporânea serventia de voltarmos a acessar aquele velho sentido. Revista Brasileira de Ciências Sociais, v. 13, n. 37, p. 43-73, jun. 1998.

QUINTANEIRO, T.; BARBOSA, M. L. DE O.; DE OLIVEIRA, M. G. Um toque de clássicos: Marx, Durkheim e Weber. Belo Horizonte: UFMG, 2012.

RODRIGUES, D. Sociologia da Religião: uma introdução. Porto: Edições Afrontamento.

RODRIGUES, D. O Erro de Nietzsche e a (não) Morte de Deus: o (des)encantamento do mundo. Política \& Sociedade, v. 16, n. 36, p. 128-142, 17 out. 2017.

WEBER, M. A ética protestante e o "espírito" do capitalismo. São Paulo: Companhia das Letras, 2004.

WEBER, M. Economia e Sociedade. Brasília: UNB, 2005.

WEBER, M. The Sociology of Religion. London: Methuen, 1922. 